\title{
Bradykinin Receptor Blockade Does Not Affect Oxygen-Mediated Pulmonary Vasodilation in Fetal Lambs
}

\author{
ANIRBAN BANERJEE, ${ }^{1}$ CHRISTINE ROMAN, AND MICHAEL A. HEYMANN \\ Cardiovascular Research Institute and the Departments of Pediatrics and Obstetrics, \\ Gynecology and Reproductive Sciences, University of California, San Francisco, San Francisco, \\ California 94143-0544
}

\begin{abstract}
Both oxygenation and rhythmic stretching of the lungs
are factors known to be responsible for pulmonary vasodiare factors known to be responsible for pulmonary vasodithat the pulmonary vasodilation caused by oxygen could be mediated, at least in part, through bradykinin release. To test this hypothesis, we evaluated the cardiovascular responses to in utero ventilation during infusion of a $\mathrm{B}_{2}$ subtype bradykinin receptor antagonist (BKA), [N-adamantaneacetyl-D-Arg ${ }^{0}, \mathrm{Hyp}^{3}, \mathrm{Thi}^{5,8}, \mathrm{D}-\mathrm{Phe}^{7} \mathrm{Jbradykinin}$ at 15-20 $\mu \mathrm{g} \cdot \mathrm{kg}^{-1} \cdot \mathrm{min}^{-1}$ in eight near-term fetal lambs and during drug vehicle infusion in five control fetal lambs. Prostacyclin synthesis was inhibited by meclofenamate infusion $\left(1.5 \mathrm{mg} \cdot \mathrm{kg}^{-1} \cdot \mathrm{h}^{-1}\right)$. Surgical placement of vascular catheters, a flow transducer around the left pulmonary artery, and a tracheostomy tube and formalin infiltration of the ductus arteriosus to maintain its patency in the presence of meclofenamate were performed $72 \mathrm{~h}$ before the study. Hemodynamic variables and pulmonary blood flow were measured and pulmonary vascular resistance was
\end{abstract}

Shortly after birth, after the onset of pulmonary ventilation, pulmonary vascular resistance and pulmonary arterial pressures fall rapidly. As a consequence, pulmonary blood flow increases approximately 8 - to 10 -fold (1). This increase in pulmonary blood flow during the transition from fetal to neonatal circulation is controlled by the interaction between several mechanical and humoral factors, which include mechanical distention of the lungs, the effects of oxygen, and the secondary release of humoral or locally vasoactive substances. Mechanical distention of the lungs and the effects of oxygenation in the fetus appear to act via different pathways. Mechanical

Received February 7, 1994; accepted April 12, 1994

Correspondence and reprint requests: Michael A. Heymann, M.D., Box 0544, HSE 1403, University of California, San Francisco, San Francisco, CA 941430544.

Supported by a grant from the National Institutes of Health (HL-40473).

'Present address: Children's Hospital Medical Center, Division of Cardiology, OSB-4, 3333 Burnet Ave., Cincinnati, OH 45229. calculated before and after in utero ventilation with $100 \%$ oxygen. Despite complete blockade by BKA of the pulmonary vasodilation produced by exogenous bradykinin, ventilation with oxygen significantly increased pulmonary blood flow by $676 \%$ over baseline state $(157.8 \pm 66$ to 1224 $\left.\pm 265 \mathrm{~mL} \cdot \mathrm{min}^{-1} \cdot 100 \mathrm{~g}^{-1}, p<0.01\right)$ and decreased the pulmonary vascular resistance by $89 \%$ from baseline state $\left(0.44 \pm 0.16\right.$ to $0.048 \pm 0.01$ torr $\left.\cdot \mathrm{mL}^{-1} \cdot \min \cdot 100 \mathrm{~g}, p<0.01\right)$. Such responses to ventilation with oxygen were comparable to those noted in the control animals, in whom bradykinin receptors had not been blocked. We conclude that bradykinin receptor blockade does not inhibit or attenuate the pulmonary vasodilatory response caused by oxygen in fetal lambs, thereby suggesting that bradykinin release is not critical for oxygen-mediated pulmonary vasodilation. (Pediatr Res 36: 474-480, 1994)

\section{EDNO, endothelium-derived nitric oxide}

distention of the lungs produces pulmonary vasodilation mainly via the cyclooxygenase pathway and prostaglandin production (2-5).

The exact mechanisms of oxygenation-induced pulmonary vasodilation remain incompletely understood. Oxygen may act directly on the smooth muscle in the vessel wall or via the release of endogenous vasoactive substances. Bradykinin was considered to be one such vasoactive substance, and the pulmonary vasodilator action of exogenous bradykinin in the fetus has been welldemonstrated (6-10). Oxygenation of the fetal lamb, by exposure to hyperbaric oxygen without ventilation, stimulates bradykinin production and also causes pulmonary vasodilation (11). Bradykinin induces the secondary release of additional vasoactive substances, including prostaglandins $(10,12)$ and EDNO (13), which could, in turn, mediate the pulmonary vasodilation produced by bradykinin. It is not known to what extent local bradykinin 
release is involved in the pulmonary vasodilation caused by oxygen or whether oxygen additionally has a direct vasodilator effect or directly induces local production of another vasoactive substance, perhaps EDNO (14).

Based on these observations and our earlier studies, which showed that oxygenation of the fetus stimulated the production of bradykinin (11), we hypothesized that the pulmonary vasodilation caused by ventilation with oxygen may be mediated through the release of bradykinin. To test this hypothesis, in near-term fetal lambs, we evaluated the effects on pulmonary blood flow and pulmonary vascular resistance of in utero ventilation with oxygen in the presence or absence of a potent bradykinin receptor antagonist.

\section{METHODS}

Surgical preparation. Thirteen mixed-breed Western ewes were operated on at 134 to $137 \mathrm{~d}$ of gestation (full term $=145$ to $150 \mathrm{~d}$ ) under epidural anesthesia with $4 \mathrm{~mL}$ of $1 \%$ tetracaine hydrochloride (Pontacaine $\mathrm{HCl}$, Winthrop Pharmaceuticals, New York, NY) supplemented with intermittent i.v. boluses of 50 to $100 \mathrm{mg}$ of ketamine hydrochloride (Ketaset, Fort Dodge Laboratories, Fort Dodge, IA) and local analgesia with $2 \%$ lidocaine hydrochloride (Xylocaine, Astra Pharmaceuticals, Westborough, MA).

With use of strict aseptic precautions, a midline laparotomy was performed to expose the uterus; through a small uterine incision, the fetal hind limb was exposed. Lidocaine hydrochloride $(1 \%)$ was infiltrated s.c., and 20 $\mathrm{mg}$ of ketamine hydrochloride were given intramuscularly to provide analgesia for the fetus. Catheters were inserted into the inferior vena cava and descending aorta of the fetus via hind-limb vessels. A catheter was also introduced into the amniotic cavity to measure amniotic fluid pressure.

Through a separate uterine incision, the left chest of the fetus was exposed; a fetal thoracotomy was performed in the third left intercostal space to expose the heart and great vessels. Succinylcholine hydrochloride (Organon, Inc., West Orange, $\mathrm{NJ}$ ) was given in a dose of 3 to $5 \mathrm{mg}$ i.v. to the fetus to prevent sudden movements. Catheters were inserted into the main pulmonary trunk, right pulmonary artery, and left atrium as previously described $(5,14)$. Constriction of the ductus arteriosus by pharmacologic interventions during the study was prevented by careful subadventitial infiltration of the ductus arteriosus with $10 \%$ buffered formalin colored with methylene blue according to previously described techniques (15). For continuous measurement of the left pulmonary arterial blood flow, a cuff-type electromagnetic flow transducer (C \& C Instruments, Los Angeles, CA) was placed around the left pulmonary artery.

The fetal neck was exposed through the same uterine incision, and catheters were introduced into the superior vena cava and ascending aorta via the jugular vein and carotid artery, respectively. For ventilation of the fetus during the experimental protocol, a 4- to 5-mm tracheostomy tube was inserted via a small incision in the midtrachea and advanced toward the carina, and the proximal trachea was ligated. To assure unobstructed drainage of tracheal fluid into the amniotic cavity, the tracheostomy tube was connected to a catheter in the amniotic cavity.

The fetal skin and uterine incisions were closed after replacing amniotic fluid losses with warm $0.9 \%$ normal saline. The abdominal incision of the ewe was closed in layers. Two million IU of penicillin G potassium (E.R. Squibb and Sons, Princeton, NJ) and $100 \mathrm{mg}$ of gentamicin sulfate (Central City Medical, Union City, CA) were administered i.v. to the ewe and into the amniotic cavity during the surgery and daily in the postoperative period. The catheters were sealed with heparinized saline and exteriorized through the abdomen to a protective pouch in the left flank of the ewe. The ewe was thereafter allowed to return to her cage for recovery. All surgical and experimental protocols were approved by the Committee on Animal Research, University of California, San Francisco.

Experimental protocol. We performed experiments $72 \mathrm{~h}$ after surgery. To block ventilation-induced prostaglandin production, on the day of the experiment a prostaglandin synthetase inhibitor, meclofenamate sodium monohydrate, was given as a bolus of $10 \mathrm{mg} / \mathrm{kg}$ over $10 \mathrm{~min}$, followed by a continuous infusion of $1.5 \mathrm{mg} \cdot \mathrm{kg}^{-1} \cdot \mathrm{h}^{-1}$ in the inferior vena cava $(5,14)$. This was infused for $4 \mathrm{~h}$ before commencing the experimental protocol, and the infusion was continued at the same rate during the entire experiment. In the experimental group of animals $(n=8)$, three conditions were studied in the following sequence: 1) baseline, 2) bradykinin antagonist infusion (producing complete blockade of bradykinin receptors as evaluated by injection of exogenous bradykinin), and 3) ventilation with $100 \%$ oxygen during bradykinin antagonist infusion. The same protocol was repeated in the control group of animals $(n=5)$ except that, instead of the bradykinin antagonist, normal saline titrated to the same $\mathrm{pH}$ (drug vehicle) was infused at the same rate.

Hemodynamic variables. The catheters were connected to Statham P23 Db transducers (Statham Instruments, Oxnard, CA), and pulmonary arterial, descending aortic, left atrial, amniotic, and tracheal pressures were recorded continuously throughout the experimental period on a direct-writing polygraph (Beckman Instruments, Schiller Park, IL). All pressures were corrected using amniotic pressure as the zero reference. For technical reasons, left atrial pressures could not be measured in two fetal lambs in the experimental group, and mean values from other fetal lambs were assigned. Fetal blood samples were obtained from the descending aorta for determination of $\mathrm{pH}, \mathrm{PCO}_{2}$, and $\mathrm{Po}_{2}$ (Corning 158 Blood Gas Analyzer, Corning Medical, Medfield, MA) as well as $\mathrm{Hb}$ concentration and oxygen saturation (OSM2 $\mathrm{He}-$ moximeter, Radiometer, Copenhagen, Denmark).

Pulmonary blood flow. Pulmonary blood flow was measured both intermittently and continuously using two 
different techniques. It was measured intermittently by the well-established radionuclide-labeled-microsphere technique (16). One batch of radioactive microspheres $(15 \mu \mathrm{m})$ was chosen at random from ${ }^{57} \mathrm{Co},{ }^{51} \mathrm{Cr},{ }^{153} \mathrm{Gd}$, ${ }^{114} \mathrm{In},{ }^{54} \mathrm{Mn},{ }^{95} \mathrm{Nb},{ }^{113} \mathrm{Sn},{ }^{85} \mathrm{Sr}$, and ${ }^{65} \mathrm{Zn}$ (New England Nuclear, Boston, MA) and injected into the superior vena cava. Reference blood samples were withdrawn from the right pulmonary artery at a rate of 3 to $5 \mathrm{~mL} / \mathrm{min}$ beginning immediately before the injection of microspheres and continuing for at least $40 \mathrm{~s}$ after the injection had been completed. Fetal or maternal blood was given to replace the blood lost.

For continuous measurement of left pulmonary arterial blood flow, an electromagnetic flow transducer of appropriate size and precalibrated in vitro using a SP 2202 flowmeter (Statham Instruments) was placed around the left pulmonary artery of all fetal lambs. Such continuous measurement of the pulmonary blood flow allowed us immediately to identify the pulmonary vasodilator responses to bradykinin, acetylcholine, and ventilation with $100 \%$ oxygen.

Pulmonary vascular resistance. This was calculated from the difference between mean pulmonary arterial pressure and mean left atrial pressure divided by the pulmonary blood flow calculated by the radioactive microsphere technique.

Baseline. Baseline measurements of arterial blood gases, all hemodynamic variables, and pulmonary blood flow were obtained as the ewe stood quietly in the study cage with free access to food and water. During this baseline condition, small boluses of bradykinin $(1 \mu \mathrm{g} / \mathrm{kg})$ and acetylcholine $(0.5 \mu \mathrm{g} / \mathrm{kg})$ were given to assure an intact endothelium-dependent vasodilatory response to these agents and in the case of bradykinin also to establish, before producing bradykinin receptor blockade, the baseline pattern and degree of response to a given dose of bradykinin.

Bradykinin antagonist infusion. In eight animals, infusion of the potent $\mathrm{B}_{2}$-kinin receptor antagonist, [ $\mathrm{N}$-adamantaneacetyl-D-Arg $\left.{ }^{0}, \mathrm{Hyp}^{3}, \mathrm{Thi}^{5,8}, \mathrm{D}-\mathrm{Phe}^{7}\right]$-bradykinin (Bachem California, Torrance, CA), was started at a rate of 15 to $20 \mu \mathrm{g} \cdot \mathrm{kg}^{-1} \cdot \mathrm{min}^{-1}$. The bradykinin antagonist was dissolved in distilled water and a small volume of normal saline, so that the volume of the vehicle infused would not affect pulmonary blood flow in any manner, and was infused into the main pulmonary artery. Ten min later, bradykinin boluses were given in gradually increasing doses of 1 to $3 \mu \mathrm{g} / \mathrm{kg}$; failure of the left pulmonary arterial blood flow (measured by the electromagnetic flow transducer) to increase with these boluses assured us of complete blockade of the bradykinin receptors. These boluses were separated by 10 -min intervals to avoid tachyphylaxis to bradykinin. An acetylcholine bolus $(0.5$ $\mu \mathrm{g} / \mathrm{kg}$ ) was given during the bradykinin antagonism to assure intact endothelium-dependent vasodilation. Once we were confident of complete blockade of bradykinin receptors, we measured arterial blood gases, hemodynamic variables, and pulmonary blood flow again.
Ventilation with $100 \%$ oxygen during bradykinin antagonist infusion. In all animals, in utero ventilation with $100 \%$ oxygen was then started during vehicle infusion (control group) or during infusion of the bradykinin antagonist (experimental group) as a continuation of the previous condition. To achieve uniform distention of the fetal lungs, Exosurf (Burroughs-Wellcome, Research Triangle Park, NC) was instilled into the lungs $1 \mathrm{~h}$ before in utero ventilation was started. To ventilate the fetus, the tubes connected to the tracheal tube were opened and tracheal fluid was allowed to drain by gravity. These tubes were then connected to a model 665 animal respirator (Harvard Apparatus, Millis, MA), and the fetus was ventilated with $100 \%$ oxygen at a ventilatory rate of 40 to 50 breaths $/ \mathrm{min}$, with an inspiratory:expiratory ratio of 0.45 and a tidal volume of 25 to $35 \mathrm{~mL}$. Carbon dioxide was not added to the oxygen because earlier studies had shown that this causes an increase in $\mathrm{PCO}_{2}$, probably due to a decrease in placental blood flow during oxygenation resulting in inadequate removal of carbon dioxide (17).

After $30 \mathrm{~min}$ of ventilation, and once hemodynamic stability was achieved, the blood gases, hemodynamic variables, and pulmonary blood flow were measured again. During ventilation, large boluses of bradykinin (3 $\mu \mathrm{g} / \mathrm{kg}$ ) were given intermittently to ensure continued blockade of bradykinin receptors.

Upon completion of the experiment, the ewe was killed by injection of a large dose of sodium pentobarbital, and the fetus was removed from the uterus and weighed. Catheter positions and the condition of the lungs were evaluated during autopsy of the fetus. The lungs were then removed, weighed, fixed in formalin, cut into small pieces, and placed in plastic vials to a uniform height of $3 \mathrm{~cm}$. Radioactivity of fetal lungs and of reference blood samples was counted in a 1000-channel pulse-height analyzer (Norland, Fort Atkinson, WI). Specific activity of each isotope within a sample was calculated by the leastsquares method (18).

Statistical analysis. All data are presented as mean \pm SD. Blood gases, hemodynamic variables, and pulmonary blood flow measurements were compared between a matched baseline state and during either vehicle (control) or bradykinin antagonist (experimental) infusion by the paired $t$ test with appropriate Bonferroni correction; similarly, measurements during either vehicle or bradykinin antagonist infusion and the subsequent ventilation period for each and also between the matched baseline state and subsequent ventilation were compared within each group (control or experimental) by the paired $t$ test with appropriate Bonferroni correction. The differences between baseline and ventilation between the control and experimental groups were compared by nonpaired $t$ test. A $p$ value of less than 0.05 indicated statistical significance.

\section{RESULTS}

The infusion of the bradykinin antagonist failed to prevent or attenuate the oxygen-mediated pulmonary va- 
sodilation, despite complete blockade of the pulmonary vasodilator effect of exogenous bradykinin (Fig. 1). The blockade of the action of bradykinin was achieved by the bradykinin antagonist after the latter had been infused for $10 \mathrm{~min}$. We found that, although the bradykinin antagonist had completely neutralized the effect of bradykinin, the pulmonary vasodilatory response to acetylcholine remained unaffected during bradykinin blockade (Fig. 1). The infusion of the bradykinin antagonist itself did not affect the blood gases (Table 1), pulmonary blood flow, or any other hemodynamic variables (Table 2 ).

In the experimental group receiving the bradykinin receptor antagonist, after 30 min of ventilation with $100 \%$ oxygen, the pulmonary blood flow calculated by the radioactive microsphere technique increased by $676 \%$ over the baseline state (from $157.8 \pm 66$ to $1224 \pm 265$ $\mathrm{mL} \cdot \mathrm{min}^{-1} \cdot 100 \mathrm{~g}^{-1} ; p<0.01$ ) (Table 2, Fig. 2). This occurred even though the pulmonary vasodilatory effect of bradykinin was completely inhibited. The corresponding pulmonary vascular resistance decreased by $89 \%$ compared with the baseline state (from $0.44 \pm 0.16$ to $0.048 \pm 0.01$ torr $\cdot \mathrm{mL}^{-1} \cdot \min \cdot 100 \mathrm{~g} ; p<0.01$ ) (Fig. 2). During ventilation with $100 \%$ oxygen there was no significant decrease in mean pulmonary arterial pressure, but there was a more than 2-fold increase in left atrial pressure $(2.7 \pm 0.8$ to $6.8 \pm 1.9$ torr; $p<0.01)$. Neither the bradykinin antagonist infusion alone nor ventilation with $100 \%$ oxygen during the bradykinin antagonist infusion caused any significant change in descending aortic pressure (Table 2).

In the control group, the effects of ventilation with $100 \%$ oxygen on pulmonary blood flow, pulmonary vascular resistance, and the other hemodynamic variables were not significantly different from those in the experimental group of fetal lambs receiving the bradykinin antagonist (Table 2, Fig. 2). The relative increase in pulmonary blood flow over the baseline state produced by oxygen ventilation was similar in both the control and experimental groups $(696 \%$ increase in the control group versus $676 \%$ increase in the experimental group; $p>0.05)$. This suggested that bradykinin receptor blockade failed not only to inhibit but also to attenuate the pulmonary vasodilator response to oxygen in fetal lambs.

Whereas the radioactive microsphere technique provided intermittent information about the pulmonary blood flow, more continuous information about the pulmonary blood flow pattern was provided by the electromagnetic flow transducer. This confirmed that, during the infusion of the bradykinin antagonist, flow in the left pulmonary artery remained unchanged. However, when ventilation with $100 \%$ oxygen was started, the pulmonary blood flow increased gradually over a period of 10 to 15 min and finally achieved a peak value, usually by $20 \mathrm{~min}$ (Fig. 1). Left pulmonary arterial blood flow, measured by the flow transducer, increased during in utero ventilation with $100 \%$ oxygen in both the experimental group $(42 \pm$ 24 to $344 \pm 86 \mathrm{~mL} / \mathrm{min} ; p<0.01$ ) and the control group ( $37 \pm 19$ to $318 \pm 39 \mathrm{~mL} / \mathrm{min} ; p<0.01$ ). There was no significant difference in the relative increase in left pulmonary arterial blood flow produced by ventilation with $100 \%$ oxygen between the control and experimental groups $(719 \%$ increase in the control group versus $759 \%$ increase in the experimental group; $p>0.05$ ). This, similar to the radioactive microsphere technique, suggested that bradykinin receptor blockade failed to inhibit or even attenuate oxygen-induced pulmonary vasodilation in fetal lambs.

This state of increased pulmonary blood flow was maintained as long as the fetus was ventilated with $100 \%$ oxygen. Once ventilation with $100 \%$ oxygen was discontinued, the pulmonary blood flow started to decrease, gradually decreased to a plateau, and finally reached the preventilation baseline state approximately 1.0 to $1.5 \mathrm{~h}$ after ventilation was discontinued.

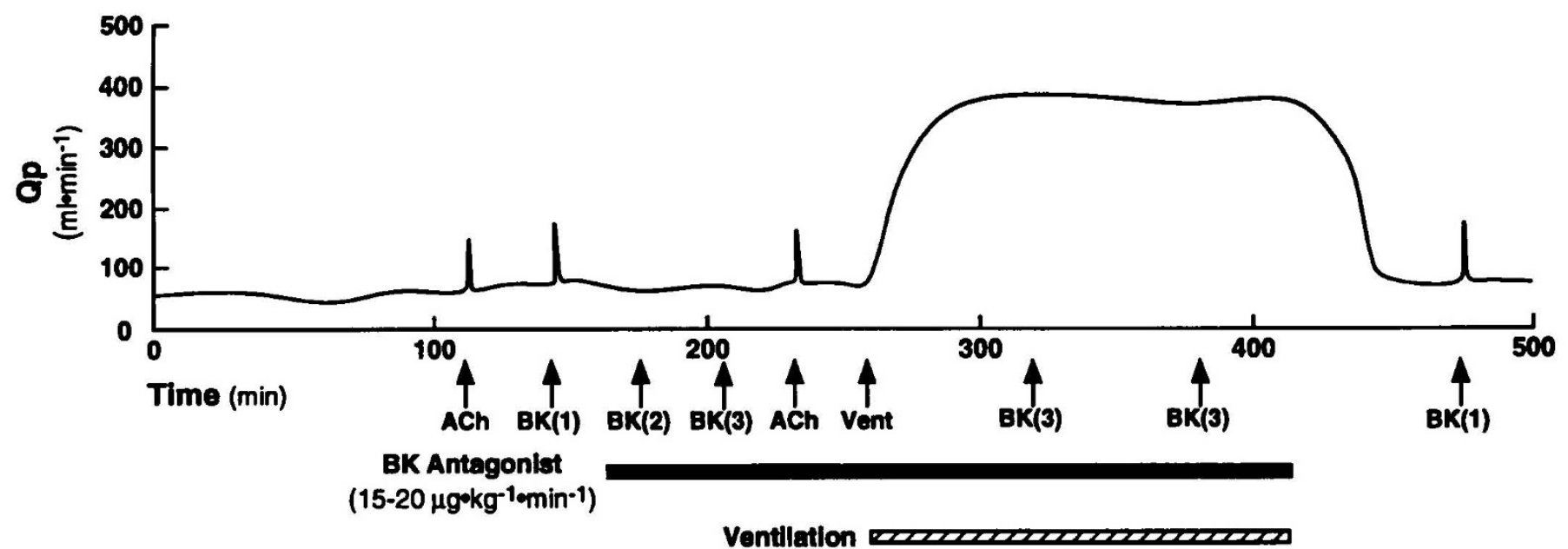

Figure 1. Typical pulmonary blood flow $(Q p)$ pattern in a fetal lamb in baseline state, during bradykinin $(B K)$ antagonist infusion, and during ventilation with $100 \%$ oxygen along with bradykinin antagonist infusion. $A C h$, acetylcholine bolus of $0.5 \mu \mathrm{g} / \mathrm{kg} ; B K(1)$, bradykinin bolus of $1 \mu \mathrm{g} / \mathrm{kg}$; $B K(2)$, bradykinin bolus of $2 \mu \mathrm{g} / \mathrm{kg} ; B K(3)$, bradykinin bolus of $3 \mu \mathrm{g} / \mathrm{kg}$; Vent, ventilation with $100 \%$ oxygen. 
Table 1. Blood gases, $\mathrm{pH}$, and oxygen saturations from descending aorta of fetal lambs in control group /receiving vehicle infusion) and experimental group (receiving bradykinin antagonist (BKA) infusion/*

\begin{tabular}{|c|c|c|c|}
\hline Hemodynamic data & Baseline & Vehicle/BKA & Vehicle/BKA $+100 \% \mathrm{O}_{2}$ \\
\hline \multicolumn{4}{|l|}{ Control group $(n=5)$} \\
\hline $\mathrm{pH}$ & $7.38 \pm 0.05$ & $7.36 \pm 0.04$ & $7.34 \pm 0.15$ \\
\hline $\mathrm{PcO}_{2}(\mathrm{kPa})$ & $6.90 \pm 0.45$ & $7.00 \pm 0.81$ & $6.60 \pm 0.86$ \\
\hline $\mathrm{Po}_{2}(\mathrm{kPa})$ & $2.60 \pm 0.21$ & $2.80 \pm 0.21$ & $21.0 \pm 13.6 \dagger$ \\
\hline $\mathrm{SO}_{2}(\%)$ & $52.1 \pm 5.2$ & $53.4 \pm 4.2$ & $96.2 \pm 5.4 \dagger$ \\
\hline $\mathrm{Hb}\left(\mathrm{g} \cdot \mathrm{dL}^{-1}\right)$ & $10.8 \pm 1.6$ & $10.6 \pm 1.6$ & $10.2 \pm 0.8$ \\
\hline \multicolumn{4}{|c|}{ Experimental group $(n=8)$} \\
\hline $\mathrm{pH}$ & $7.36 \pm 0.03$ & $7.35 \pm 0.13$ & $7.33 \pm 0.15$ \\
\hline $\mathrm{PCO}_{2}(\mathrm{kPa})$ & $6.80 \pm 0.73$ & $7.20 \pm 0.73$ & $6.70 \pm 0.86$ \\
\hline $\mathrm{Po}_{2}(\mathrm{kPa})$ & $2.90 \pm 0.28$ & $2.80 \pm 0.42$ & $24.8 \pm 12.2 \dagger$ \\
\hline $\mathrm{SO}_{2}(\%)$ & $53.6 \pm 4.5$ & $51.6 \pm 2.7$ & $97.7 \pm 8.4 \dagger$ \\
\hline $\mathrm{Hb}(\mathrm{g} / \mathrm{dL})$ & $11.2 \pm 1.9$ & $10.9 \pm 0.8$ & $10.7 \pm 0.6$ \\
\hline
\end{tabular}

* Values are mean $\pm \mathrm{SD}$. $\mathrm{SO}_{2}$, oxygen saturation.

$\dagger p<0.05 v s$ baseline condition within the group and $v s$ previous condition within the group.

\section{DISCUSSION}

The aim of our study was to investigate the role of bradykinin as one possible intermediary vasoactive substance in oxygen-mediated pulmonary vasodilation. We showed that in fetal lambs complete blockade of bradykinin receptors does not inhibit or attenuate the pulmonary vasodilatory response to ventilation with oxygen.

Concentrations of free bradykinin are higher in umbilical venous and arterial cord blood than in maternal venous blood (19). Also, exogenous bradykinin is a potent pulmonary vasodilator (6-10), and bradykinin is released from fetal lungs with ventilation or during hyperbaric oxygenation $(11,20)$. Thus, we considered that bradykinin might be one intermediary substance involved in oxygen-induced pulmonary vasodilation. Recently, the development of specific bradykinin receptor antagonists $(21,22)$ has allowed further examination of this hypothesis. Bradykinin and related kinins act via two receptors designated as $\mathbf{B}_{1}$ and $\mathrm{B}_{2}$ receptors (23). Bradykinin has a high affinity for binding to the $\mathbf{B}_{2}$ receptors and a low affinity for binding to $B_{1}$ receptors (24). Both in bovine pulmonary artery endothelial cells and in porcine vascular endothelial cells $(24,25)$, stimulation of bradykinin receptors by bradykinin causes the production or release of EDNO. The EDNO enhances the production of cyclic GMP $(13,26)$, which in turn mediates vascular smooth muscle relaxation. Only $B_{2}$ receptor antagonists, and not
$\mathrm{B}_{1}$ receptor antagonists, were able to inhibit this production of cyclic GMP in bradykinin-stimulated endothelial cells (25).

For these reasons we decided to use a potent $B_{2}$ receptor antagonist, [N-adamantaneacetyl-D-Arg ${ }^{0}, \mathrm{Hyp}^{3}$, $\mathrm{Thi}^{5,8}, \mathrm{D}-\mathrm{Phe} \mathrm{C}^{7}$-bradykinin, to evaluate the role of bradykinin in oxygen-induced pulmonary vasodilation in fetal lambs. This bradykinin antagonist is, in fact, an analog bradykinin with amino acid substitutions at positions 3 (proline), 5 (phenylalanine), 7 (proline), and 8 (phenylalanine) with L-4-hydroxyproline (Hyp), $\beta$-2-thienyl-Lalanine (Thi), D-phenylalanine (D-Phi), and $\beta$-2-thienyl-Lalanine (Thi), respectively. In addition to these substitutions, adamantaneacetyl-D-arginine is added to the $\mathrm{N}$-terminal residue $(21,22)$. This bradykinin analog is a competitive antagonist of bradykinin and is more potent than some of the $B_{2}$ receptor antagonists synthesized earlier $(22,24)$. The $B_{2}$ receptor blockade is dose dependent (24) and, in our studies at a continuous infusion rate of $60 \mu \mathrm{g} / \mathrm{min}\left(15-20 \mu \mathrm{g} \cdot \mathrm{kg}^{-1} \cdot \mathrm{min}^{-1}\right)$, it completely blocked the pulmonary vasodilator action of bradykinin. Repeated boluses of gradually increasing doses of bradykinin failed to elicit a pulmonary vasodilator response during infusion of this bradykinin antagonist.

The continuous infusion of a bradykinin antagonist failed to prevent or attenuate the significant pulmonary vasodilation caused by oxygen in fetal lambs. This indi-

Table 2. Effect of 30 min of ventillation with $100 \%$ oxygen on hemodynamic data obtained from control group of animals and group of animals receiving bradykinin $(B K)$ receptor antagonist*

\begin{tabular}{|c|c|c|c|c|c|c|}
\hline \multirow[b]{2}{*}{ Hemodynamic data } & \multicolumn{3}{|c|}{ Control } & \multicolumn{3}{|c|}{ BK receptor antagonist } \\
\hline & $\begin{array}{l}\text { Baseline } \\
(n=5)\end{array}$ & $\begin{array}{l}\text { Vehicle } \\
(n=5)\end{array}$ & $\begin{array}{l}100 \% \text { oxygen } \\
(n=5)\end{array}$ & $\begin{array}{l}\text { Baseline } \\
(n=8)\end{array}$ & $\begin{array}{l}\text { BK antagonist } \\
\quad(n=8)\end{array}$ & $\begin{array}{c}100 \% \text { oxygen } \\
(n=8)\end{array}$ \\
\hline Pulmonary blood flow ( $\mathrm{mL} \cdot \mathrm{min}^{-1} \cdot 100 \mathrm{~g}^{-1}$ ) & $167 \pm 74$ & $151 \pm 88$ & $1330 \pm 597 \dagger$ & $157.8 \pm 66$ & $146 \pm 97$ & $1224 \pm 265 \dagger$ \\
\hline $\begin{array}{l}\text { Pulmonary vascular resistance } \\
\quad\left(\text { torr } \cdot \mathrm{mL}^{-1} \cdot \min \cdot 100 \mathrm{~g}\right)\end{array}$ & $0.46 \pm 0.16$ & $0.42 \pm 0.23$ & $0.044 \pm 0.02 \dagger$ & $0.44 \pm 0.16$ & $0.44 \pm 0.2$ & $0.048 \pm 0.01 \dagger$ \\
\hline Pulmonary artery pressure-mean (torr) & $70 \pm 9.4$ & $68 \pm 8.2$ & $65 \pm 5$ & $67 \pm 6.2$ & $65 \pm 8.8$ & $64 \pm 3.8$ \\
\hline Left atrial pressure-mean (torr) & $3.3 \pm 1.1$ & $2.6 \pm 0.7$ & $6.6 \pm 107 \dagger$ & $2.7 \pm 0.8$ & $3.1 \pm 1.5$ & $6.8 \pm 1.9 \dagger$ \\
\hline Descending aortic pressure-mean (torr) & $70.5 \pm 8.1$ & $67 \pm 5.5$ & $72 \pm 3.3$ & $69 \pm 7.1$ & $64 \pm 7.2$ & $66 \pm 6.7$ \\
\hline
\end{tabular}

* Values are mean $\pm \mathrm{SD}$.

$\dagger p<0.05 v s$ baseline condition within the group and $v s$ previous condition within the group. 

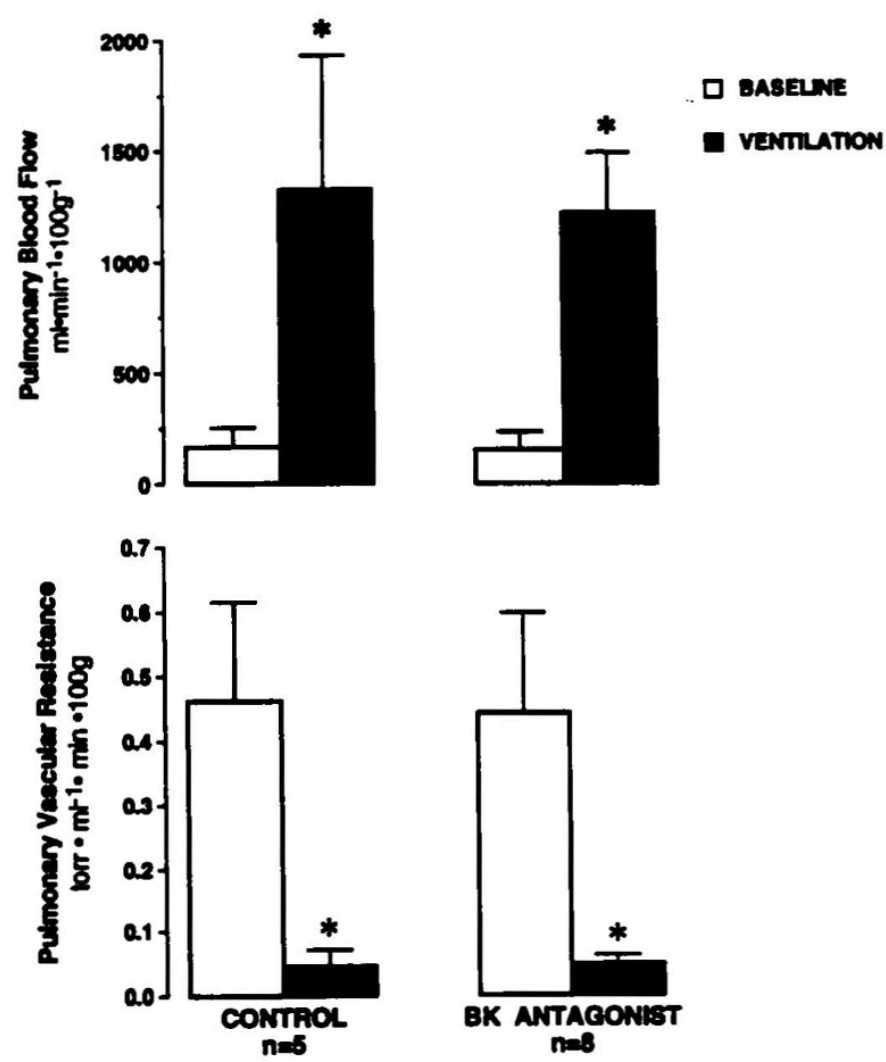

Figure 2. Effects of ventilation with $100 \%$ oxygen on pulmonary blood flow and pulmonary vascular resistance in fetal lambs in the control group and in the group receiving the bradykinin $(B K)$ antagonist. ${ }^{*}, p<$ 0.05 for comparisons between baseline condition and oxygen ventilation in each group.

cates that oxygen-induced vasodilation may not be mediated only through the release of bradykinin. From our experiments, it appears more likely that oxygen may act either directly on the vascular smooth muscle or by some yet unknown mechanism that stimulates the production of EDNO. Although done in adult animals, which might respond differently, recent in vitro studies have shown that hypoxia causes a decrease in the concentration of cyclic GMP and a consequent decrease in EDNO activity in both rabbit (26) and rat (27) pulmonary artery segments. Hypoxia also impairs EDNO production in bovine pulmonary artery endothelial cells (28). Therefore, a possible interplay between oxygen and EDNO may be responsible for the pulmonary vasodilation seen with oxygen. Alternatively, oxygen may inhibit the production of pulmonary vasoconstrictors, e.g. leukotrienes. Endorgan antagonism (receptor blockade) of leukotrienes in fetal lambs increases pulmonary blood flow about 8-fold, close to the levels expected with normal ventilation after birth (29).

Because distention of fetal lungs stimulates the release of prostaglandins, also important regulators of pulmonary blood flow $(5,20)$, we inhibited prostaglandin production with meclofenamate, thereby avoiding the confounding effects of lung distention on pulmonary blood flow. Because vascular relaxation produced by bradykinin requires an intact endothelium and is mediated via
EDNO $(13,25,30)$, we also assured endothelial integrity in our preparation by injecting acetylcholine, which acts through a different (muscarinic) receptor.

In summary, this study in fetal lambs shows that bradykinin receptor blockade does not inhibit or attenuate the well-known pulmonary vasodilatory response caused by oxygen, thereby suggesting that bradykinin release is not essential for oxygen-induced pulmonary vasodilation. It is possible that oxygen acts mainly by the release of EDNO in the endothelium or by a direct effect on the vascular smooth muscle.

Acknowledgments. The authors thank Dr. Walker Long, Burroughs Wellcome Co. for kindly supplying the Exosurf used in these studies; we also acknowledge the expertise and assistance of Mario Trujillo, Bruce D. Payne, and Carl McWatters.

\section{REFERENCES}

1. Fineman R, Soifer SJ, Heymann MA 1991 The role of pulmonary vascular endothelium in perinatal pulmonary circulatory regulation. Semin Perinatol 15:58-62

2. Cassin S 1980 Role of prostaglandins and thromboxanes in the control of the pulmonary circulation in the fetus and newborn. Semin Perinatol 4:101-107

3. Leffler CW, Hessler JR, Terragno NA 1980 Ventilation-induced release of prostaglandin-like material from fetal lungs. Am J Physiol 238:H282-H286

4. Leffler CW, Hessler JR, Green RS 1984 The onset of breathing at birth stimulates pulmonary vascular prostacyclin synthesis. Pediatr Res 18:938-942

5. Velvis H, Moore P, Heymann MA 1991 Prostaglandin inhibition prevents the fall in pulmonary vascular resistance as a result of rhythmic distension of the lungs in fetal lambs. Pediatr Res 30:62-68

6. Campbell AGM, Dawes GS, Fishman AP, Hyman AI, Perks AM 1968 The release of a bradykinin-like pulmonary vasodilator substance in foetal and newborn lambs. J Physiol (Lond) 195:83-96

7. Assali NS, Johnson GH, Brinkman III CR, Huntsman DJ 1971 Effects of bradykinin on the fetal circulation. Am J Physiol 221:1375-1382

8. Gilbert RD, Hessler JR, Eitzman DV, Cassin S 1973 Effect of bradykinin and alterations of blood gases on fetal pulmonary vascular resistance. Am J Physiol 225:1486-1489

9. Accurso FJ, Wilkening RB 1988 Temporal response of the fetal pulmonary circulation to pharmacologic vasodilators. Proc Soc Exp Biol Med 187:89-98

10. Frantz E, Soifer SJ, Clyman RI, Heymann MA 1989 Bradykinin produces pulmonary vasodilatation in fetal lambs: the role of prostaglandin production. J Appl Physiol 67:1512-1517

11. Heymann MA, Rudolph AM, Nies AS, Melmon KL 1969 Bradykinin production associated with oxygenation of the fetal lamb. Circ Res 25:521-534

12. McIntyre TM, Zimmerman GA, Satoh K, Prescott SM 1985 Cultured endothelial cells synthesize both platelet-activating factor and prostacyclin in response to histamine, bradykinin, and adenosine triphosphate. J Clin Invest 76:271-280

13. Ignarro LJ, Byrns RE, Buga GM, Wood KS 1987 Mechanisms of endothelium-dependent vascular smooth muscle relaxation elicited by bradykinin and VIP. Am J Physiol 253:H1074-H1082

14. Moore P, Velvis H, Fineman JR, Soifer SJ, Heymann MA 1992 EDRF inhibition attenuates the increase in pulmonary blood flow due to oxygen ventilation in fetal lambs. J Appl Physiol 73:2151-2157

15. Rudolph AM, Heymann MA, Fishman N, Lakier JB 1975 Formalin infiltration of the ductus arteriosus: a method for palliation of infants with selected congenital cardiac lesions. N Engl J Med 292:1263-1268

16. Heymann MA, Payne BD, Hoffman JIE, Rudolph AM 1977 Blood flow measurements with radionuclide-labeled particles. Prog Cardiovasc Dis 20:55-79

17. Teitel DF, Iwamoto HS, Rudolph AM 1987 Effects of birth-related events on central blood flow patterns. Pediatr Res 22:557-566

18. Baer RW, Payne BD, Verrier ED, Vlahakes GJ, Molodowitch D, Uhlig PN, Hoffman JIE 1984 Increased number of myocardial blood flow measurements with radionuclide-labeled microspheres. Am J Physiol 246:H418-H434

19. Melmon KL, Cline MJ, Hughes T, Nies AS 1968 Kinins: possible mediators of neonatal circulatory changes in man. J Clin Invest 47:1295-1302

20. Leffler CW, Hessler JR, Green RS 1984 Mechanism of stimulation of pulmonary prostacyclin synthesis at birth. Prostaglandins 28:877-887

21. Vavrek RJ, Stewart JM 1985 Competitive antagonists of bradykinin. Peptides 6:161-164

22. Schachter M, Uchida Y, Longridge DJ, Labedz T, Whalley ET, Vavrek RJ, Stewart JM 1987 New synthetic antagonists of bradykinin. Br J Pharmacol 92:851-855 
23. Regoli D, Barabe J 1980 Pharmacology of bradykinin and related kinins. Pharmacol Rev 32:1-46

24. Sung CP, Arieth AJ, Shikano K, Berkowitz BA 1988 Characterization and function of bradykinin receptors in vascular endothelial cells. J Pharmacol Exp Ther 247:8-13

25. Schini VB, Boulanger C, Regoli D, Vanhoutte PM 1990 Bradykinin stimulates the production of cyclic GMP via activation of $\mathrm{B}_{2}$ kinin receptors in cultured porcine aortic endothelial cells. J Pharmacol Exp Ther 252:581-585

26. Johns RA, Linden JM, Peach MJ 1989 Endothelium-dependent relaxation and cGMP accumulation in rabbit pulmonary artery are selectively impaired by moderate hypoxia. Circ Res 65:1508-1515
27. Rodman DM, Yamaguchi T, Hasunuma K, O'Brien RF, McMurtry IF 1990 Effects of hypoxia on endothelium-dependent relaxation of rat pulmonary artery. Am J Physiol 258:L207-L214

28. Warren JB, Maltby NH, MacMcormack D, Barnes PJ 1989 Pulmonary endothelium-derived relaxing factor is impaired in hypoxia. Clin Sci 77:671-676

29. Soifer SJ, Loitz RD, Roman C, Heymann MA 1985 Leukotriene end organ antagonists increase pulmonary blood flow in fetal lambs. Am J Physiol 249:H570-H576

30. Furchgott RF 1984 The role of endothelium in the responses of vascular smooth muscle to drugs. Ann Rev Pharmacol Toxicol 24:175-197

\section{ANNOUNCEMENT Search for European Chief Editor \\ Pediatric Research}

After five years of service, the European Editorial Board of Pediatric Research will complete its term on December 31, 1995. The Board of Trustees of the International Pediatric Research Foundation has established a Search Committee to review the credentials of qualified candidates for a new European Chief Editor and to make recommendations to the Board, which has the responsibility for final selection.

The Search Committee seeks candidates or recommendations for individuals who might serve as European Chief Editor. The European Chief Editor must be a member of the European Society for Pediatric Research. Interested individuals should submit six copies of their curriculum vitae and those of at least four individuals in their locale to serve as Associate Editors. In addition, the application should include suggestions for further improving the quality of Pediatric Research and its growth as a unique biomedical publication. The office carries a budget for supporting staff and an honorarium. Additional information regarding the operation of the European Office can be obtained from the current European Editor, Pieter J. J. Sauer, M.D., Sophia Children's Hospital, Dr. Molewaterplein 60, 3015 GJ Rotterdam, The Netherlands.

The Search Commitee will interview selected candidates immediately before the annual meeting of the Board of Trustees in September 1995. Applications should be sent before February 1, 1995, to: Gunnar Sedin, M.D., Chairman, Search Committee, Department of Pediatrics, Uppsala University Children's Hospital, S-751 85 Uppsala, Sweden. 